\title{
A PRÁTICA PARTICIPATIVA DO FÓRUM PRÓ-TRABALHO: PROMOÇÃO DA LEI DE COTAS E DA INCLUSÃO PRODUTIVA DAS PESSOAS COM DEFICIÊNCIA
}

\author{
THE PARTICIPATORY PRACTICE OF THE FORUM WORK: PROMOTING THE \\ QUOTA LAW AND THE PRODUCTIVE INCLUSION OF PEOPLE WITH \\ DISABILITIES
}

\author{
Maria Cristina Abreu Domingos Reis ${ }^{1}$
}

1 Mestre em Gestão Social, Educação e Desenvolvimento Local pelo Centro Universitário UNA, Professora de Pós-graduação da UNESAV. crisabreis@hotmail.com

\section{ART ICLE INFO}

Article history:

Received 2018-10-03

Accepted 2019-02-06

Available online 2019-02-07
Palavras-chave: Gestão Social. Participação. Inclusão Produtiva. PCD. Lei de Cotas.

Keywords: Social Management. Participation. Productive Inclusion. PCD. Quota Law.

RESUMO. Este estudo analisou o processo da gestão social participativa, de um Fórum de atuação em Belo Horizonte e região metropolitana, que visa promover o cumprimento da Lei de Cotas referente a inserção produtiva das Pessoas com Deficiência (PCD); Fórum Pró-Trabalho das Pessoas com Deficiência e Reabilitadas (FPT). Utilizou-se abordagem qualitativa por meio da observação participante, análise documental do regimento e atas (de 2008 a 2010), através do software Atlas TI, entrevista semiestruturada com seis participantes e um egresso do fórum. No âmbito da gestão social do FPT, nas atas analisadas o segmento governamental ocupa maior participação nos debates, e as PCD demonstraram baixo nível de interlocução na tessitura das propostas, e as empresas apresentaram baixa participação. Percebeu-se que $o$ FPT não realiza processos de monitoramento e avaliação quanto ao tipo de inserção produtiva realizada, prevalecendo procedimentos de inclusão marginal quanto a inclusão produtiva. Essas observações não retiram a relevância do fórum, pois constitui espaço de reinvindicação e análise das contradições sociais quando discutidas questões relativas à inclusão produtiva de PCD.

ABSTRACT. This study analyzed the process of social management and the performance of a participatory forum, working in Belo Horizonte and metropolitan region, not established by law, which aims to promote compliance with the Law of Quotas referring to the productive insertion of People with Disabilities; Forum Pró-Work of People with Disabilities and Rehabilitated. A qualitative approach was used through participant observation, documentary analysis of the regiment (from 2008 to 2010), through Atlas $\mathrm{TI}$ software, semi-structured interview with six participants and one egress from the forum. In the context of the social management of the People with Disabilities and Rehabilitated, in the analyzed reports the government segment occupies a greater participation in the debates, and the DPCs showed a low level of dialogue in the proposal structure, and the companies presented low participation. It was noticed that the People with Disabilities and Rehabilitateddoes not carry out 
monitoring and evaluation processes regarding the type of productive insertion made, with practices classified as marginal inclusion procedures with a performance not oriented by productive inclusion. These observations do not detract from the relevance of the forum, since it constitutes a space for invoking and analyzing social contradictions when discussing issues related to the productive inclusion of People with Disabilities.

\section{INTRODUÇÃO}

Este trabalho faz parte de um estudo acerca do Fórum Pró-Trabalho das PCDs (Pessoa com Deficiência) quando realizei minha dissertação de mestrado em Gestão Social, Educação e Desenvolvimento Local dentro da linha de pesquisa Processos Políticos Sociais, Articulações Institucionais e Desenvolvimento Local na UNA-MG (Centro Universitário Una). Quanto ao fórum, trata-se de um espaço de articulação e participação que se estabeleceu pela adesão voluntária da sociedade civil e do poder público, com o envolvimento de sindicatos, universidades, entidades "de" e "para" pessoas com deficiência, tanto públicas quanto privadas, bem como empresas.

Sendo assim, este estudo traçou como objetivo principal analisar como um fórum intersetorial participativo, não instituído por lei, se organizava para promover um processo que garantisse a sua finalidade, do ponto de vista da gestão social e da inclusão produtiva. Nesse movimento de construção do trabalho investigativo foi formulada a seguinte questão problema: Quais são os limites e possibilidades de atuação de um fórum dedicado à inserção produtiva da PCD do ponto de vista da gestão social e da participação?

A metodologia utilizada se pautou por uma abordagem qualitativa através de observação participante, análise documental do regimento e das atas (de 2008 a 2010), por meio do software Atlas TI, e entrevista semiestruturada com seis participantes e um egresso do fórum.

O resultado das análises do material levantado pelo estudo indicou que a defesa do direito ao trabalho das pessoas com deficiência por meio do fórum não se dá de forma recorrente, já que suas intervenções acontecem de modo intermitente devido a certa instabilidade dos seus processos de organização. Entretanto ficou evidenciado que distintos fatores e limitações contribuíam para os diferentes níveis de envolvimento e participação dos seus participantes, como a baixa frequência nas plenárias, condução autoritária de algumas lideranças, e a reduzida presença das próprias PCDs. Dentre as diversas tensões que atravessam esse espaço coletivo de discussão e reivindicação de direitos, destaca-se o 
protagonismo exacerbado do setor público, o qual fragiliza o interesse e a implicação da sociedade civil em debater questões relativas a essa população.

Entretanto, essas observações não retiram a relevância do fórum, pois representa um dos poucos espaços de discussão dos direitos das PCD. Por outro lado, constituem indicadores importantes para se rever práticas coletivas de participação, pois um setor da sociedade não pode se sobrepor a outros grupos organizados da coletividade quando se pretende construir relações participativas e democráticas, no âmbito das instâncias políticas que reivindicam direitos civis. De todo modo, seria ingênuo acreditar que a reunião de distintos setores sociais produziria relações harmônicas entre seus membros, já que o conflito se constitui na diversidade e gera novos processos sociais de reconstrução das relações coletivas (DEMO, 2000, p.80).

Diante disso, no próximo tópico, defendo a importância de um projeto em rede para a promoção de políticas públicas de inclusão produtiva para as PCDs.

\section{DESENVOLVIMENTO}

\section{Nos meandros de um projeto de rede de inclusão}

Ao analisar uma organização de defesa dos direitos à ocupação remunerada das PCD, denominado Fórum Pró-Trabalho das Pessoas com Deficiência e Reabilitadas (FPT), que se mobiliza em torno da defesa do direito ao trabalho por meio da Lei de Cotas, foi possível observar fatores, de sua práxis, relacionados à inserção produtiva e à gestão social, em especial quanto à participação dos sujeitos participantes.

A pesquisa evidenciou a capacidade do movimento social em se mobilizar por meio de um fórum baseado numa gestão compartilhada entre distintos setores sociais, de maneira democrática e dialógica, contribuindo para o alcance de seus objetivos, apesar das condições precárias de manutenção das estruturas que sustentam esse tipo de organização.

Do ponto de vista da mobilização de atores sociais, foi possível perceber a contribuição desse espaço como local de controle social no acompanhamento da política pública, possibilitando o fomento em prol da real situação de emprego para as PCD e de sua efetiva "inclusão social pelo trabalho".

O que se destacou nessa temática foi a importância de se ocupar arenas nas quais a sociedade civil tenha a capacidade de articulação e mobilização como estratégia de promoção da cidadania. 
Como o FPT promove ações relacionadas à Lei de Cotas, foi necessário conhecer essa política afirmativa instituída para garantir direitos ainda não afirmados na sociedade e suas implicações do ponto de vista da maneira como vem sendo cumprida a legislação.

Foi constatado que o fórum apresenta limites em sua atuação. Ele não possuía um processo de acompanhamento e monitoramento que poderia fornecer conhecimento em profundidade acerca dos tipos de ocupação que estão sendo oferecidas às PCDs, ou mesmo um mapeamento, monitoramento e avaliação da qualidade de inserção realizada ou a própria consequência dessa inserção para a vida dos sujeitos com deficiência.

Diante dessas considerações, a proposta deste estudo a respeito do tema da inserção produtiva foi estudada no intuito de verificar se existe alguma avaliação do FPT quanto ao tipo de inserção real no mundo do trabalho. Nesta investigação partiu-se da concepção de inclusão produtiva, conforme conceitua o MDS:

Todo processo conducente à formação de cidadãos integrados ao mundo do trabalho tem como perspectiva a conquista da autonomia para uma vida digna sustentada por parte de todas as pessoas amparadas ou fragilmente vinculadas à produção de renda e riqueza (BRASIL, 2011ª).

Revendo esse conceito, essa inserção refere-se à condição social e econômica do sujeito que, por meio do trabalho, adquire acesso e mobilidade social para atingir um patamar que Ihe propicie autonomia e melhoria na sua situação de vida.

\section{3- METODOLOGIA}

As entrevistas foram realizadas com seis membros participantes do FPT e um exparticipante. O roteiro abordou variáveis que contribuíram para melhor compreender questões referentes ao seu grau de institucionalização, aos princípios que os orienta, suas finalidades, limites e possibilidades da inclusão produtiva e quanto à questão da gestão (gerenciamento).

Dessa maneira, foi possível compreender que o tipo de inserção produtiva que estava sendo praticada na sociedade se caracterizava como uma inclusão marginal e/ou precária, segundo Martins (1997), tendo em vista os cargos e atribuições que eram atribuídas às PCD, sem perspectiva de mobilidade social, como também devido à baixa escolaridade e falta de qualificação profissional desses sujeitos, tendo em vista a fragilidade das políticas de educação inclusiva e inclusão digital. 
$\mathrm{Na}$ análise documental, priorizou-se analisar o regimento e as atas referentes a 2008, 2009 e 2010. Esse período destacou-se pela sistematização regular dos registros, apesar da constatação de que as atas não são descritivas na íntegra e não possuem regularidade descritiva nas suas transcrições. Ainda assim, por ser uma organização não instituída por lei, a análise das informações oportunizou recolher dados significativos para o estudo.

Nesse processo, como recurso metodológico para a análise das atas, utilizou- se o software Atlas TI. Tal instrumento tecnológico também foi utilizado nos estudos de Avritzer (2010) e foi orientado pela análise de conteúdo, neste caso com ênfase na comunicação dos participantes nas plenárias. Isso permitiu analisar a capacidade de vocalização dos sujeitos, na perspectiva Setorial (poder público, setor empresarial ou as entidades de organizações governamentais), no sentido de captar quem fala mais, a capacidade de proposição de cada participante, destacando nesse campo o papel preponderante do poder público.

\section{4- QUANTO À INCLUSÃO PRODUTIVA: ALGUMAS TENSÕES EVIDENCIADAS NO FPT}

Os elementos de análise, portanto, demonstraram forte poder de vocalização do poder público em um fórum essencialmente com característica de "não institucionalizado por lei" (distinto de conselhos de políticas públicas, por exemplo), que se estrutura pelas necessidades e demanda social do segmento social de PCD. O peso do governo no funcionamento do fórum parece ser inquestionável, tanto na viabilização de espaço, em alguns períodos marcantes, e eventos com recursos financeiros.

Quanto à proposição e aprovação de propostas de ação, as diversas instâncias governamentais representadas pareciam efetivar uma liderança inconteste no Fórum. Entretanto, deve-se atentar para que não gere relações hegemônicas por parte do poder público frente às demais. As entrevistas revelaram certo receio de participantes da sociedade civil em relação ao controle do FPT pelo Estado. Essa informação foi também confirmada nas entrevistas.

Nesse aspecto, tanto nas entrevistas quanto na análise das atas destaca-se que as empresas que dele participam parecem estar mais interessadas em ouvir, trocar experiência e buscar conhecimento sobre a temática. Ademais, poderiam estar mobilizadas a participar da entidade (FPT), diante de um certo reconhecimento institucional, uma vez que nesse locus existia forte presença de representantes de instituições governamentais encarregadas de fiscalizar a aplicação das leis, e no caso de não cumprimento, impor multas. 
Contudo, todos esses fatores apresentavam possibilidades para que o fórum se tornasse um espaço de discussão das contradições sociais reveladas na sua própria configuração, constituindo-se assim como um lugar de interação e aprendizagem para a formulação de políticas públicas nesse campo social.

Outro interesse das empresas participantes parece buscar implantar instrumentos que facilitem a elas o cumprimento das exigências legais para emprego de PCD, o que é demonstrado pela importância que dão à discussão do Portal Rede de Inclusão.

Dessa maneira, observou-se que quanto à participação, a defesa de direitos das PCD não se dá de forma linear e homogênea do ponto de vista setorial (governo, ONGs e empresas).

Frente a essas considerações, ficou evidente que a participação das PCD nos vários campos de diálogo e discussão e espaços democráticos como o FPT necessita ser repensada de forma que o próprio sujeito se envolva, defenda e garanta seu direito. Ou seja, conforme Pateman (1992, apud GOHN, 2001), espera-se que assumam "participação total" nas situações que tenham correspondência com sua realidade.

Cabe ressaltar que a participação representa um elemento preponderante em organizações de gestão social, tal como o Fórum, que por seu caráter democrático tornam as pessoas realmente parte integrante desse locus.

Nesse sentido, é oportuno reafirmar que a prática paradigmática fundamentada na participação, parceria e interação dos sujeitos na vida social possibilita a aquisição de conhecimento, aprendizagem, estímulos e oportunidades, substituindo ambientes segregatórios e discriminatórios. Percebe-se, portanto, que está em formação uma nova visão e um novo paradigma da inclusão, o qual a sociedade passa a concebê-los também como sujeitos de direitos com deficiência, substituindo paulatinamente o paradigma anterior marcado por visões preconceituosas e práticas assistencialistas e caritativas destinadas aos indivíduos com deficiência.

Nesse aspecto, o marco legal, por meio da Convenção dos Direitos das PCDs recentemente adotada no Brasil, bem como a Lei Brasileira da Inclusão (Lei n 13.146 de 6 de julho de 2015) também chamada de Estatuto da Pessoa com Deficiência, bem como as legislações anteriores que avançam no combate à discriminação contra a PCD nas questões relacionadas a formas de emprego, em todas as etapas e condições de trabalho, tais como, seleção, recrutamento, contratação, admissão, permanência no emprego, 
ascensão profissional, condições seguras e salubres de trabalho, e mesmo o trabalho forçado ou compulsório.

Destaca-se também a proteção ao direito trabalhista em igual condição aos demais trabalhadores, o que se denomina de igualdade de oportunidades, com seus devidos direitos e consequentes deveres, com igual remuneração por trabalho de igual valor, além da reparação de injustiças e assédio moral.

Além disso, as PCD necessitam de garantias para condições de acesso à orientação profissional técnica, reabilitação profissional, oportunidade de trabalho autônomo, empreendedorismo, oportunidade de emprego em órgãos públicos e privados. Ressalta-se assegurar as adaptações razoáveis, não se desprezando a contundente necessidade de implementação da acessibilidade, em suas dimensões: urbanísticas, arquitetônicas, programáticas, tecnológicas, metodológicas, comunicacionais e atitudinais. Essas intervenções colaboram e possibilitam as condições ajustáveis para que o trabalhador com deficiência possa, portanto, ser incluído de maneira adequada nas suas especificidades.

Esse rol de exigências constituem alguns elementos balizadores que o Ministério do Trabalho e Emprego e o Ministério Público do Trabalho, por meio de suas publicações e orientações, com o apoio de grupos organizados, vem esclarecendo, conscientizando, ouvindo os sujeitos e ONGs, fiscalizando e realizando um trabalho profícuo, com o compromisso de que essas diretrizes para promoção do emprego remunerado para as PCDs sejam cumpridas (BRASIL, 2000 c).

Dessa maneira, pode-se afirmar que as conquistas das PCD caminham para a inclusão produtiva e da cidadania não tutelada (DEMO, 2002), na perspectiva da autonomia, empoderamento e emancipação socioeconômica das PCD.

Todavia, apesar dos estudos defenderem a perspectiva da inclusão produtiva, ainda prevalece a inclusão marginal ou precária e tutelada, uma vez que, no debate atual e nas próprias entrevistas, a qualidade da inserção realizada não tem destaque privilegiado nas discussões do fórum, não sendo essa uma posição muito diferente da realidade em curso.

Os pontos listados a seguir foram identificados na pesquisa e também, muitas vezes, identificados como argumentos impeditivos, conforme salientam as empresas para o avanço da inserção produtiva das PCD, os quais podem constituir-se como um diagnóstico de características e particularidades da situação ou mesmo contribuir para rupturas com visões arcaicas e preconceituosas que necessitam ser revistas e gerenciadas nos ambientes empresariais para que se garanta a plena participação e a inclusão produtiva das PCD na sociedade no momento histórico atual: 
- As PCD possuem baixo índice de escolaridade, em função da exclusão vivenciada nos sistemas educacionais.

- As PCD ainda não estão qualificadas.

- O nível de exigência de escolaridade das empresas é elevado. Há competição do Benefício de Prestação Continuada (BPC) e do Benefício da Previdência com a remuneração do trabalho da PCD. Boa parte das pessoas acaba desistindo do trabalho em função da parca estabilidade oferecida pelo benefício.

- Devido ao preconceito e discriminação vivenciados, as PCD relatam dificuldades em acreditar nas suas potencialidades, inclusive a laboral.

- As entidades que defendemos direitos das PCD ainda não possuem cadastro de PCD aptas e qualificadas conforme o desejo e exigências das empresas, para o mercado de trabalho.

- As PCD ainda não sabem onde procurar oportunidades de trabalho.

- As empresas oferecem vagas; porém as PCD "não sabem onde encontrá- la".

- As empresas não possuem conhecimento sobre as especificidades desse público.

- As empresas não estão dispostas a investir nas diversas acessibilidades necessárias, impossibilitando o acesso de pessoas com certas deficiências aos postos de trabalho.

- A maioria das empresas não está disposta a fazer concessões e/ou adequações específicas para as PCDs.

- As empresas não percebem o emprego de PCD como exigência de cumprimento da legislação, mas como uma benesse ou como ação de responsabilidade social.

- Faltam campanhas de sensibilização para o meio empresarial.

- Deve-se envolver as famílias das pessoas com maiores comprometimentos na fase que antecede os programas de capacitação e inclusão laboral, possibilitando conhecimento e segurança aos familiares, no sentido de evitar posturas de superproteção ou tutela das famílias junto às PCD.

Este artigo não investigou diretamente esses impedimentos reais e alegados nas entrevistas, quanto ao emprego de PCD, ainda que a busca de identificação do conceito de "inclusão produtiva" nas práticas do FPT tangenciasse alguns deles. Assim, cabe uma postura crítica no intuito de desconstruir as abordagens assistencialistas e preconceituosas, que desconsideram o propósito da inclusão e da cidadania autônoma, e que não contribuem para a emancipação dos sujeitos. 
A sugestão que se pode fazer, nesse aspecto, refere-se à busca de transpor esses obstáculos por meio de tecnologias sociais, que podem significar pontos de partida para outros estudos (BRASIL, 2005). Entretanto, a partir desta pesquisa, a principal ferramenta que se apresenta relaciona-se ao desafio dos gestores para a implantação de programas dessa natureza na perspectiva da gestão social.

Da análise das entrevistas realizadas neste estudo com os participantes, constatouse que eles têm visões diferenciadas sobre os princípios e a finalidade do FPT. Por outro lado, ficou evidenciado que o FPT representa a possibilidade de ser lugar de promoção, aprendizagem, troca de informações e instrumentalização para seus participantes.

Os participantes compartilhavam o interesse em defendê-lo como espaço democrático e de articulação de redes, ainda que vejam dificuldades no seu funcionamento (coordenação autoritária para uns, comunicação manipulada para outros, a excessiva dedicação à constituição do Portal da Inclusão e a absorção do Fórum pelo Estado ainda para outros). Muitas vezes, um aparente caos, identificado em momentos de crises, exigia que se reconstruíssem e organizassem saberes, como também promovia o compartilhamento de experiências.

Entende-se que esses espaços apresentam limitações e necessitam melhorar a sua capacidade de comunicação, articulação, mobilização e escuta, com o objetivo de ampliar e fortalecer suas ações. Além disso, detectou-se a necessidade da oferta de instâncias formadoras e oferta de formação para seus membros.

A GS representa um "modo de fazer" complexo, em que se emaranhavam distintos fatores, atribuições, interesses e trajetórias. Mas a práxis do FPT se aproxima da caracterização do modelo inclusivo e sinalizava a convergência com os conceitos de GS (Gestão Social) do ponto de vista de suas características, finalidades e funções. Nesse contexto, resgata-se o conceito de GS de Maia (2005, p. 15-16).

Assim, compreendemos a gestão social como um conjunto de processos sociais com potencial viabilizador do desenvolvimento societário emancipatório e transformador. É fundada nos valores, práticas e formação da democracia e da cidadania, em vista do enfrentamento às expressões da questão social, da garantia dos direitos humanos universais e da afirmação dos interesses e espaços públicos como padrões de uma nova civilidade. Construção realizada em pactuação democrática, nos âmbitos local, nacional e mundial; entre os agentes das esferas da sociedade civil, sociedade política e da economia, com efetiva participação dos cidadãos historicamente excluídos dos processos de distribuição das riquezas e do poder. 
Tal definição pode parecer utópica em uma sociedade capitalista, mas parece, sobretudo, estar mais próxima e adequada, apresentando a possibilidade de pavimentar o caminho para se alcançar a tessitura de uma gestão que atenda às necessidades e demandas específicas para situações sociais mais injustas de grupos historicamente vulneráveis, tais como as das PCDs.

\section{CONCLUSÃO}

A contribuição deste estudo destaca a riqueza de fóruns de iniciativa da sociedade civil, voltados para defesa dos direitos humanos de populações vulnerabilizadas, como o caso das PCD, composto pela diversidade de seus componentes com sua característica baseado no modelo intersetorial e dialógico. O campo de gestão social ou de gestão do desenvolvimento social apresenta-se como uma grande possibilidade, um reflexo das práticas e do multiconhecimento construído por múltiplas disciplinas, delineando-se uma proposta multiparadigmática, de natureza interdisciplinar.

As organizações sociais estão sempre redefinindo as suas práticas e adquirindo novos conhecimentos. Portanto, se reorganizam e se ressignificam de acordo com o momento histórico, político e social. Todavia, a obrigatoriedade do cumprimento das cotas apresenta essa característica peculiar de exigir a superação de obstáculos, o que possibilitará inovação, busca de ajudas técnicas e até mesmo desenvolvimento local nos territórios vulneráveis. São novas práticas que, ao se realizarem, adquirem significados e formas para subsidiar o alcance da tão necessária justiça pela inclusão social.

Dessa maneira, do ponto de vista de limites e possibilidades, a inclusão produtiva necessita, em primeiro lugar, ser entendida como um conceito permeado de valores emancipatórios do sujeito em sua vida econômica social e cultural, mais bem desenvolvida em um contexto de GS. Por outro lado, o FPT, no período estudado, demonstrou maior preocupação com a racionalidade instrumental (relacionada aos fins) em detrimento da racionalidade substantiva (em relação aos seus valores), ao centrar suas discussões e debates na Rede de Inclusão. Tal encaminhamento não invalida seu campo de organização e possibilidades, que se materializa pela prática de construção e decisão coletiva dos atores envolvidos em prol da inclusão social.

No caso das políticas públicas para as PCDs, justifica-se a criação de espaços sistemáticos de construção coletiva, com orientação teórico-prática entre a sociedade civil e 
o poder público, com características e valores teórico-conceituais da gestão social, necessários por propiciar espaço de participação, mobilização, diversidade, proposição, aprendizagem, promoção de valores, busca de finalidades, reflexão, comunicação e ações estratégicas de enfrentamento que, para além das cotas legais, desconstruam paradigmas, preconceitos e discriminações.

\section{REFERÊNCIAS}

AVRITZER, Leonardo. A dinâmica da participação local do Brasil (org.) São Paulo: Cortez, 2010. Coleção Pensando a Democracia Participativa; v. 3, 2010.

AVRITZER, Leonardo. Participação e distribuição nas políticas públicas do Nordeste. Relatório. Belo Horizonte: UFMG, 2009.

BRASIL. Lei no 10.048, de 8 de novembro de 2000. Disponível em: http://www.mpes.gov.br/anexos/centros apoio/arquivos/15 205816422172008 - Lei 2010.048-0020- 0 Prioridade-20 de 20 atendimento.pdf.

BRASIL. Lei no 8.213, de 24 de julho de 1991. Disponível em: http://www.planalto.gov.br/ccivil/leis/L8213 compilado.htm.

DEMO, Pedro. A educação pelo avesso: assistência como direito e como problema. 2. ed., São Paulo: Cortez, 2002.

DEMO, Pedro. Política social: sobre futuros do combate à pobreza. Petrópolis, Rio de Janeiro: Vozes, 2000.

GOHN, Maria da Glória. Conselhos gestores e participação sociopolítica. São Paulo: Cortez, 2001.

GOHN, Maria da Gloria. Educação não formal e o educador social: atuação no desenvolvimento de projetos sociais. São Paulo: Cortez, 2010.

MAIA, Marilene. Gestão social: reconhecendo e construindo referenciais. Revista Virtual Textos \& Contextos, n. 4, dez. 2005.

MARTINS, José de Souza. Exclusão social e a nova desigualdade. São Paulo: Paulus, 1997. 